\title{
EffectorP 3.0: Prediction of Apoplastic and Cytoplasmic Effectors in Fungi and Oomycetes
}

\author{
Jana Sperschneider ${ }^{1, \dagger}$ and Peter N. Dodds ${ }^{2}$ \\ ${ }^{1}$ Biological Data Science Institute, The Australian National University, Canberra, Australia \\ ${ }^{2}$ Black Mountain Science and Innovation Park, CSIRO Agriculture and Food, Canberra, Australia
}

Accepted 24 October 2021.

\begin{abstract}
Many fungi and oomycete species are devasting plant pathogens. These eukaryotic filamentous pathogens secrete effector proteins to facilitate plant infection. Fungi and oomycete pathogens have diverse infection strategies and their effectors generally do not share sequence homology. However, they occupy similar host environments, either the plant apoplast or plant cytoplasm, and, therefore, may share some unifying properties based on the requirements of these host compartments. Here, we exploit these biological signals and present the first classifier (EffectorP 3.0) that uses two machinelearning models: one trained on apoplastic effectors and one trained on cytoplasmic effectors. EffectorP 3.0 accurately predicts known apoplastic and cytoplasmic effectors in fungal and oomycete secretomes with low estimated false-positive rates of 3 and $8 \%$, respectively. Cytoplasmic effectors have a higher proportion of positively charged amino acids, whereas apoplastic effectors are enriched for cysteine residues. The combination of fungal and oomycete effectors in training leads to a higher number of predicted cytoplasmic effectors in biotrophic fungi. EffectorP 3.0 expands predicted effector repertoires beyond small, cysteine-rich secreted proteins in fungi and RxLR-motif containing secreted proteins in oomycetes. We show that signal peptide prediction is essential for accurate effector prediction, because EffectorP 3.0 recognizes a cytoplasmic signal also in intracellular, nonsecreted proteins.
\end{abstract}

Keywords: fungus-plant interactions, oomycete-plant interactions

Eukaryotic filamentous pathogens encompass fungi and oomycetes that cause extensive damage to plants, including those providing food, fiber, and biofuels (Savary et al. 2019). Although oomycetes and fungi are not close phylogenetic relatives, they have very similar filamentous morphology and infection structures. These pathogens can broadly be classified according to their infection strategy: biotrophic pathogens grow and feed on living host tissue, hemibiotrophic pathogens switch to a necrotrophic phase after feeding on living tissues for some time, and necrotrophic pathogens kill host cells and feed on

${ }^{\dagger}$ Corresponding author: J. Sperschneider; Jana.Sperschneider@csiro.au

*The $\boldsymbol{e}$-Xtra logo stands for "electronic extra" and indicates that supplementary data and supplementary tables are published online.

The author(s) declare no conflict of interest.

(c) (1) () () Copyright $\odot 2022$ The Author(s). This is an open access article distributed under the CC BY-NC-ND 4.0 International license. dead tissues (Glazebrook 2005). Pathogens and symbionts of plants use secreted proteins termed effectors to facilitate infection by suppressing plant defense responses and altering host cell structure and function (Lo Presti et al. 2015). Pathogens secrete effectors into the host extracellular space (the plant apoplast) as well as into the intracellular space (the plant cytoplasm). Apoplastic effectors can either function in the apoplast (De Wit 2016) or they can be bound to the fungal cell wall (Tanaka and Kahmann 2021). In contrast, cytoplasmic effectors are delivered into the plant cell and some may subsequently target specific plant cell compartments. Effector delivery into host cells is well characterized in bacteria, nematodes, and insects (Galán et al. 2014; Mitchum et al. 2013; Rodriguez and Bos 2013). For example, bacteria have conserved secretion systems such as the type III secretion system to directly inject effectors into the plant cell, and nematodes use a stylet to infect effectors into the host cell.

Effector delivery mechanisms in fungi and oomycetes remains elusive (Lo Presti and Kahmann 2017). In Magnaporthe oryzae, cytoplasmic effectors preferentially accumulate in the biotrophic interfacial complex (Khang et al. 2010) whereas apoplastic effectors follow the conventional secretory pathway (Giraldo et al. 2013). In Ustilago maydis, a stable protein complex of five effectors and two membrane proteins has been suggested to be involved in effector translocation; however, these proteins are not broadly conserved across fungi (Ludwig et al. 2021). The presence of conserved sequence motifs in sequencedivergent oomycete effectors has been implicated in effector delivery (Whisson et al. 2007). The RxLR motif occurs in the $\mathrm{N}$-terminal sequence after the signal peptide cleavage site and is often followed by an acidic stretch of amino acids. However, experimental validation of RxLR-mediated effector uptake has been debated (Ellis and Dodds 2011), with recent evidence pointing toward a role of the RxLR motif in effector cleavage before secretion (Wawra et al. 2017). Furthermore, the RxLR motif is not conserved outside Phytophthora spp. and downy mildews. The WY domain is a structural domain associated with cytoplasmic oomycete effectors from the order Peronosporales that has been used to identify effector candidates with degenerate RxLR motifs (Wood et al. 2020). Similarly, degenerate RxLR motif searches have been applied in Pythium spp. that lack effectors with a canonical RxLR motif (Ai et al. 2020). The LxLFLAK sequence motif defines the crinkling- and necrosisinducing family (CRN) proteins and is also commonly used to search for CRN effectors (Schornack et al. 2010). Although, in oomycetes, sequence motif and Hidden Markov Model searches are well-established methods to predict some classes of cytoplasmic effectors, they will miss bona fide effectors that do not carry such motifs or domains as well as apoplastic effectors (Wood et al. 2020). 
Computational effector prediction in fungi is challenging because fungal effectors do not share sequence similarities or conserved sequence motifs. In fungi, early approaches have been biased toward prioritizing small, cysteine-rich proteins as effector candidates (Sperschneider et al. 2015a; Stergiopoulos and de Wit 2009). We introduced a contrasting approach with the first machine-learning tool for effector prediction, EffectorP 1.0, which overcame the inefficiencies and bias of these approaches (Sperschneider et al. 2016). An updated version (EffectorP 2.0) retrained on a larger data set and incorporating a machine-learning ensemble learner resulted in higher prediction accuracy (Sperschneider et al. 2018a). Complementary approaches for effector prediction include transcriptomic-based approaches that filter for effector candidates expressed during infection (Gervais et al. 2017; Palma-Guerrero et al. 2017), sequence-based secreted protein clustering methods (Pedersen et al. 2012; Saunders et al. 2012), or genome-wide association studies (Sánchez-Vallet et al. 2018). Recently, EffectorP 1.0 and 2.0 effector prediction scores together with secretion prediction and functional annotations have been used to automatically rank effector candidates (Jones et al. 2021).

One shortcoming of earlier versions of EffectorP (1.0 and 2.0 ) is that they are not able to predict the most likely localization of the effector. To address this, ApoplastP (Sperschneider et al. 2018b) and LOCALIZER (Sperschneider et al. 2017) have been developed for effector localization prediction in plant cells. Both tools have demonstrated that there is a localization signal in the effector protein sequence that can be exploited. Although ApoplastP predicts localization of proteins to the plant apoplast (Sperschneider et al. 2018b), it has not been trained to distinguish effector proteins from noneffector proteins. Similarly, LOCALIZER is able to predict intracellular protein localization to the plant chloroplast, mitochondria, or nucleus but is not able to distinguish effectors from noneffectors (Sperschneider et al. 2017). Furthermore, EffectorP 1.0 and 2.0 have been trained only on fungal effectors, not oomycete effectors. A deep-learning method called deepredeff can predict effectors in bacteria, fungi, and oomycetes (Kristianingsih and MacLean 2021) but does not return effector localization. EffectorO is a machine-learning method for effector prediction trained on the $\mathrm{N}$ terminus of effector sequences but it is applicable to oomycetes only (Nur et al. 2021). Here, we propose that the data sets of experimentally validated effectors together with their localization are now sufficient to train two parallel machinelearning classifiers: one using apoplastic fungal and oomycete effectors and the other using cytoplasmic fungal and oomycete effectors. This results in EffectorP 3.0, the first method that can predict whether a secreted fungal or oomycete protein is one of these three types: an apoplastic effector, a cytoplasmic effector, or a noneffector.

\section{RESULTS}

\section{Training of EffectorP 3.0 for prediction} of apoplastic and cytoplasmic effectors.

We first curated positive training sets of fungal and oomycete effectors with experimental support. We classified these effectors into apoplastic or cytoplasmic according to experimental evidence from the literature. If such evidence was absent, we classified effectors according to the infection strategy of the pathogen. After sequence homology reduction, 64 apoplastic effectors (50 from fungi and 14 from oomycetes) and 112 cytoplasmic effectors (77 from fungi and 35 from oomycetes) remained as positive training data (Table 1). For the negative training sets, we predicted secretomes from a wide range of fungal and oomycete genomes (Supplementary Table S1). We curated five secreted protein sets that are likely depleted in different effector classes: (i) a homology-reduced set of secreted proteins with an RxLR motif from plant-pathogenic oomycetes together with secreted proteins from biotrophic or hemibiotrophic fungi ( $n=25,643$; likely depleted in apoplastic effectors), (ii) a homology-reduced set of secreted proteins without an RxLR motif from plant-pathogenic oomycetes together with secreted proteins from necrotrophic or hemibiotrophic fungi ( $n=$ 30,912 ; likely depleted in cytoplasmic effectors), (iii) a set of secreted fungal saprophyte proteins and secreted proteins from brown algae ( $n=28,080$; likely depleted in effectors), (iv) a set of secreted fungal ectomycorrhizal proteins ( $n=14,357$; likely depleted in cytoplasmic effectors), and (v) a set of secreted proteins from animal-pathogenic fungi and animal-pathogenic oomycetes ( $n=5,181$; likely depleted in apoplastic effectors). Proteins in the negative sets that shared sequence homology to an effector in the positive training set were excluded.

We used an ensemble learning approach of classifiers that each are trained on a different subset of negative training data (Fig. 1). Overall, we chose a total of 60 best-performing models (Supplementary Table S2) comprising 5 Naïve Bayes classifiers and 5 C4.5 decision trees that discriminate between apoplastic effectors and secreted pathogen proteins, 5 Naïve Bayes classifiers and $5 \mathrm{C} 4.5$ decision trees that discriminate between apoplastic effectors and secreted saprophyte or brown algae proteins, 5 Naïve Bayes classifiers and $5 \mathrm{C} 4.5$ decision trees that discriminate between apoplastic effectors and secreted animal-pathogenic pathogen proteins, 5 Naïve Bayes classifiers and 5 C4.5 decision trees that discriminate between cytoplasmic effectors and secreted pathogen proteins, 5 Naïve Bayes classifiers and 5 C4.5 decision trees that discriminate between cytoplasmic effectors and secreted saprophyte or brown algae proteins, and 5 Naïve Bayes classifiers and $5 \mathrm{C} 4.5$ decision trees that discriminate between cytoplasmic effectors and secreted fungal ectomycorrhizal proteins. To generate EffectorP 3.0, we combined these 30 apoplastic and 30 cytoplasmic models into an ensemble classifier where each model has seen a different subset of negative training data and, for a given protein sequence input, returns a probability of whether it is (i) an apoplastic effector, (ii) a cytoplasmic effector, or (iii) a noneffector. If a secreted protein is predicted as both an apoplastic and cytoplasmic effector, EffectorP 3.0 reports it as dual-localized and the class with the highest probability as its primary localization. Because the number of cytoplasmic fungal effectors is sufficiently large, we also used this positive set to train a fungal-specific cytoplasmic model with the same negative data sets and then combined this model with the apoplastic model as above to generate EffectorP-fungi 3.0.

\section{EffectorP 3.0 has improved accuracy and accurately distinguishes} between apoplastic and cytoplasmic localization.

To ensure that EffectorP 3.0 is not overfitted and simply memorizes the training data, we collected independent positive and negative test sets. First, a validation set of 48 unseen fungal and oomycete effectors (Supplementary Table S3) was used. EffectorP 3.0 correctly predicted $44(91.7 \%)$ of these as effectors (Table 2). The deep-learning tool deepredeff (Kristianingsih and MacLean 2021) predicted only $56.3 \%$ effectors in the validation set correctly. Of the 32 fungal effectors in the set, EffectorP 3.0 and EffectorP-fungi 3.0 both predicted $90.6 \%$ correctly, whereas EffectorP 2.0 only predicted $74.2 \%$ correctly. For the 16 oomycete effectors in the set, EffectorP 3.0 predicted 15 $(93.8 \%)$ correctly. The EffectorP-fungi 3.0 model predicted only $81.2 \%$ of the oomycete effectors correctly, highlighting that a fungal-specific model does not accurately predict oomycete effectors. The same holds for EffectorP 2.0, which was not 
trained on oomycete effectors and predicted only $43.8 \%$ of oomycete effectors correctly. The oomycete effector prediction tool EffectorO (Nur et al. 2021) also predicted a high proportion of the oomycete validation set correctly (14 of 16 effectors, $87.5 \%$ ). Taken together, EffectorP 3.0 is a more sensitive tool for effector prediction in both fungi and oomycetes than EffectorP 2.0 or deepredeff. We also used a set of secreted fungal saprophyte proteins and secreted proteins from brown algae $(n=28,080)$ as negative test data. This set is depleted for effectors; however, it will contain some effector-like proteins. Thus, the false-positive rate on this set was a conservative estimation because effector-like proteins are expected to be predicted as effectors by all of the prediction methods. EffectorP 3.0 predicted $21.8 \%$ as effectors $(9.4 \%$ cytoplasmic and $12.4 \%$ apoplastic) and the balanced accuracy [(sensitivity + specificity)/2] on the positive and negative test sets was approximately $85 \%$. All other tested methods displayed lower balanced accuracy
(EffectorP $2.0=81.6 \%$; deepredeff-fungi $=62 \%$; deepredeffoomycetes $=56.1 \%$; and EffectorO $=74.5 \%$ ).

We also estimated EffectorP's false-positive rate for apoplastic and cytoplasmic effector predictions in more detail (Table 3). We first used apoplastic plant proteins (proteins detected in apoplastic proteomics experiments with a predicted signal peptide) as well as fungal carbohydrate-active enzymes and secreted saprophyte proteins $(n=26,258)$. These sets are expected to be depleted in cytoplasmic proteins and enriched for secreted apoplastic proteins. From these sets, we estimated that EffectorP 3.0 has a false-positive rate for cytoplasmic effector prediction of $8.3 \%$ (EffectorP-fungi $3.0=6.6 \%$ ). We then collected cytoplasmic plant proteins, human proteins, bacterial type-III effectors, as well as fungal nonsecreted proteins with a predicted signal peptide such as those retained in the endoplasmic reticulum or Golgi apparatus, those directed to the vacuole, and those with glycosylphosphatidylinositol anchors $(n=24,705)$. All of these

Table 1. Fungal and oomycete effectors that were used in the training of EffectorP $3.0^{\mathrm{a}}$

\begin{tabular}{|c|c|c|}
\hline Species & Apoplastic effector training set & Cytoplasmic effector training set \\
\hline Melampsora lini & - & $\begin{array}{l}\text { AvrM, AvrL567, AvrP123, AvrP4, AvrM14, } \\
\text { AvrL2 }\end{array}$ \\
\hline Uromyces viciae-fabae & - & RTP1 \\
\hline Puccinia graminis f. sp. tritici & - & AvrSr50, AvrSr35 \\
\hline P. striiformis f. sp. tritici & PstSCR1 & PEC6, PST02549, PNPi \\
\hline Phakopsora pachyrhizi & 年 & PpEC23, CSEP-07, CSEP-09 \\
\hline Blumeria graminis f. sp. hordei & CSEP0055 & $\begin{array}{l}\text { AVRa1, AVRa13, BEC1011, BEC4, } \\
\text { BEC1019, CSEP0105, CSEP0162, } \\
\text { CSEP0254, CSEP0081 }\end{array}$ \\
\hline B. graminis f. sp. tritici & - & AvrPm3 \\
\hline Cladosporium fulvum & $\begin{array}{l}\text { Avr9, Avr4, Avr4E, Avr2, Avr5, } \\
\text { ECP6, ECP2, ECP1, ECP5, ECP4, } \\
\text { ECP7, CfTom1 }\end{array}$ & - \\
\hline Leptosphaeria maculans & $\begin{array}{l}\text { AvrLm1, AvrLm11, AvrLmJ1, AvrLm2, } \\
\text { AvrLm3 }\end{array}$ & AvrLm4-7 \\
\hline Fusarium oxysporum f. sp. lycopersici & SIX1, SIX2, SIX4, SIX6, SIX7 & SIX3, SIX5, SIX8 \\
\hline Fusarium oxysporum f. sp. melonis & - & Avrfom2 \\
\hline F. oxysporum Fo5176 & - & Foa3, Foa4 \\
\hline Magnaporthe oryzae & BAS4, MC69, Slp1, Msp1, Pemg1 & $\begin{array}{l}\text { MoHTR1, MoHTR2, AVR-Pita1, Pwl1, } \\
\text { AVR-Pia, BAS1, BAS2, BAS3, AvrPiz-t, } \\
\text { AVR-Pii, AVR-Pik, BAS107, AvrPib, lug6, } \\
\text { lug9, MoHEG13, SPD2, SPD4, SPD7, SPD9, } \\
\text { SPD10, BAS162, AvrPi9, Pwl2, Avr1-C039 }\end{array}$ \\
\hline Verticillium dahlia & Ave1 & Vdlsc1, VdSCP7, PevD1, VdSCP41 \\
\hline Rhynchosporium commune & NIP1, NIP2, NIP3 & - \\
\hline Ustilago maydis & Pep1, Pit2, Rsp3, Apb73 & Cmu1, eff1-1, See1, Mig2-2, Jsi1, Tin2 \\
\hline U. hordei & $-2-$ & UhAvr1 \\
\hline Sporisorium reilianum & - & SAD1 \\
\hline Pyrenophora tritici-repentis & ToxB & - \\
\hline Parastagonospora nodorum & Tox1, Tox3 & ToxA \\
\hline Botrytis cinerea & NEP1 & - \\
\hline Zymoseptoria tritici & AvrStb6, Zt6, Mg1lysm & - \\
\hline Colletotrichum graminicola & Cgfl & CgEP1 \\
\hline F. graminearum & FGL1, XylA & - \\
\hline Piriformospora indica & FGB1 & PIIN_08944 \\
\hline Sclerotinia sclerotiorum & - & SsSSVP1 \\
\hline Penicillium expansum & Lysm1 & - \\
\hline Laccaria bicolor & - & MISSP7, MISSP7.6 \\
\hline Rhizophagus irregularis & - & SIS1 \\
\hline$R$. intraradices & - & SP7 \\
\hline Colletotrichum orbiculare & NIS1 & - \\
\hline Phytophthora infestans & INF1, EPI10, INF2B, EpiC1, EPI1 & $\begin{array}{l}\text { AVR3a, Avr2a, Avr2b, Avr3b, Avr4, } \\
\text { AvrVnt1, Avrblb1, Avrblb2, CRN1, CRN2, } \\
\text { CRN8, CRN16, PexRD2, PITG_03192, } \\
\text { Avr1, SNE1 }\end{array}$ \\
\hline P. sojae & GIP2, PsXEG1, GP42, NIP1, GIP1 & $\begin{array}{l}\text { AVR1B-1, Avh5, Avh241, Avr1k, Avr1d, } \\
\text { CRN63, PsAvr3b, PsAvr3c, PsAvr4_6, } \\
\text { Avr3b, Pslsc1, Avh18a1, Avr1a, Avr3a }\end{array}$ \\
\hline$P$. parasitica & CBEL, OPEL, NPP1 & - \\
\hline P. cactorum & $\mathbf{P c F}$ & - \\
\hline Hyaloperonospora arabidopsidis & - & ATR13, ATR1, ATR1, ATR5, ATR39-1 \\
\hline
\end{tabular}

${ }^{\mathrm{a}}$ Effectors with literature evidence for apoplastic or cytoplasmic localization are highlighted in bold. 
sets are expected to be depleted in apoplastic effectors. From these sets, we estimated that EffectorP 3.0 has a false-positive rate for apoplastic effector prediction of $2.5 \%$ (EffectorP-fungi $3.0=2.4 \%)$

Finally, we applied EffectorP 3.0 to the cytoplasmic and apoplastic effectors that have experimental evidence for their localization from both the training and validation sets (Table 4). In all, $80 \%$ of the 110 cytoplasmic effectors were predicted correctly as cytoplasmic with EffectorP 3.0. The eight cytoplasmic effectors incorrectly predicted as apoplastic were RTP1 (Uromyces viciae-fabae), PpEC23 (Phakopsora pachyrhizi), Foa3 (Fusarium oxysporum Fo5176), AvrPiz-t (M. oryzae), SsSSVP1 (Sclerotinia sclerotiorum), HvEC_016 (Hemileia vastatrix), AvrPm2 (Blumeria graminis f. sp. tritici), and AVRa9 (B. graminis f. sp. hordei). These effectors ranged in sequence length from 102 to 291 amino acids (aa), with a cysteine number of 3 to 20 (cysteine content $=2.3$ to $6.9 \%$ ). Thus, a high cysteine content together with a small size could be the reason for the apoplastic mispredictions. A further seven cytoplasmic effectors were predicted as dual-localized effectors with apoplastic as the class with highest probability: AvrP123 (Melampsora lini), SIX5 (F. oxysporum f. sp. lycopersici), AvrLm4-7 (Leptosphaeria maculans), AVR-Pii and AvrPi9 (Magnaporthe oryzae), ToxA (Parastagonospora nodorum), and AvrSr27
(Puccinia graminis f. sp. tritici). These effectors ranged in sequence length from 70 to 143 aa, with a cysteine number of 2 to 15 (cysteine content $=1$ to $10.4 \%$ ). Although these effectors were incorrectly predicted with apoplastic as their most likely localization, they were still being predicted as cytoplasmic albeit with a lower probability. For example, AvrP123 is a cytoplasmic effector from the rust fungus $M$. lini with 11 cysteines and a small size of 117 aa (9.4\% cysteine content), and the cysteine residues are involved in zinc binding instead of disulfide bond formation (Zhang et al. 2018). EffectorP 3.0 predicts AvrP123 as cytoplasmic with probability 0.77 and apoplastic with probability 0.8 , thus still recognizing the cytoplasmic signal despite the high cysteine content. Similarly, AvrSr27 is a cytoplasmic effector from the rust fungus $P$. graminis f. sp. tritici with 15 cysteines and a small size of 144 aa (10.4\% cysteine content) (Upadhyaya et al. 2021). Again, EffectorP 3.0 recognized the cytoplasmic signal and predicted AvrSr27 as cytoplasmic with probability 0.72 and apoplastic with probability 0.78 . Finally, we note that EffectorP 3.0 predicted $51.3 \%$ of cytoplasmic plant proteins as cytoplasmic effectors. This suggests that EffectorP 3.0 also will recognize a cytoplasmic signal in intracellular proteins. Thus, for accurate effector prediction, EffectorP should only be applied to proteins with computational or experimental evidence for secretion.

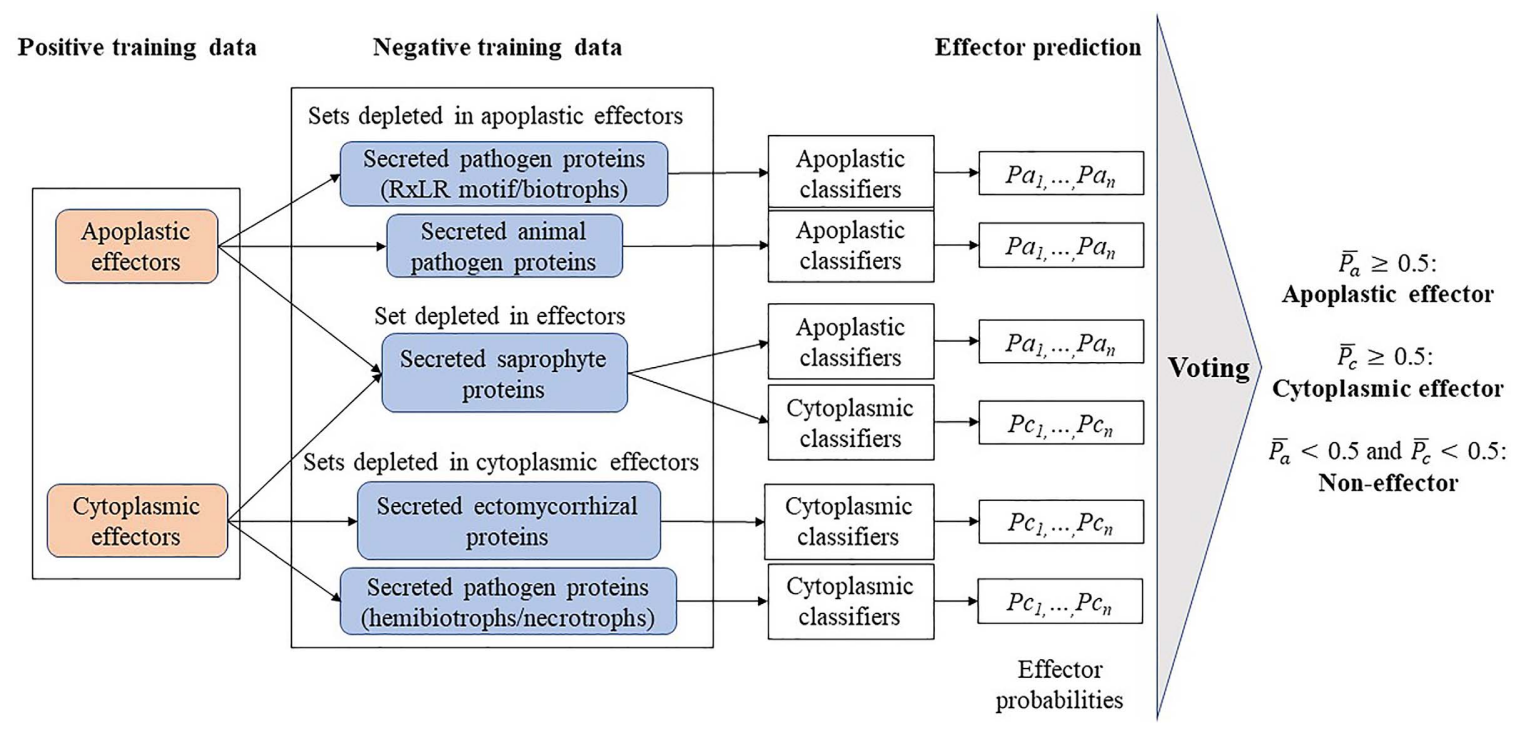

Fig. 1. Workflow of EffectorP 3.0. Positive training data are apoplastic and cytoplasmic effectors and negative training data are five different sets of secreted proteins. We trained an ensemble of apoplastic and cytoplasmic classifiers and soft voting was used to arrive at a final prediction for an unseen secreted protein. If a secreted protein is predicted as both apoplastic and cytoplasmic, it is reported as dual-localized, and the class with the higher probability is assigned as its most likely localization.

Table 2. Predicted effectors for different independent test sets ${ }^{\mathrm{a}}$

\begin{tabular}{|c|c|c|c|c|c|c|c|}
\hline Test set & Proteins $(n)$ & EffectorP 3.0 & $\begin{array}{l}\text { EffectorP- } \\
\text { fungi } 3.0\end{array}$ & EffectorP 2.0 & $\begin{array}{c}\text { deepredeff } \\
\mathbf{0 . 1 . 1} \text { (fungi) }\end{array}$ & $\begin{array}{c}\text { deepredeff } \\
\text { 0.1.1 } \\
\text { (oomycetes) }\end{array}$ & EffectorO \\
\hline $\begin{array}{l}\text { Effector validation } \\
\text { set (fungi) }\end{array}$ & 32 & $29(90.6 \%)$ & $29(90.6 \%)$ & $23(74.2 \%)$ & $22(68.8 \%)$ & NA & NA \\
\hline $\begin{array}{l}\text { Effector validation } \\
\text { set (oomycetes) }\end{array}$ & 16 & $15(93.8 \%)$ & NA & NA & NA & $5(31.3 \%)$ & $14(87.5 \%)$ \\
\hline $\begin{array}{l}\text { Secreted proteins } \\
\text { from fungal } \\
\text { saprophytes and } \\
\text { brown algae }\end{array}$ & 28,080 & $6,124(21.8 \%)$ & $5,508(19.6 \%)$ & $3,089(11 \%)$ & $12,565(44.8 \%)$ & $5,350(19.1 \%)$ & $10,830(38.6 \%)$ \\
\hline Balanced accuracy & - & $85 \%$ & $85.5 \%$ & $81.6 \%$ & $62 \%$ & $56.1 \%$ & $74.5 \%$ \\
\hline
\end{tabular}

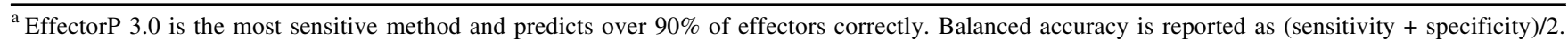
$\mathrm{NA}=$ not applicable. Numbers in bold indicate the highest numbers of predicted effectors. 


\section{Cytoplasmic effectors are enriched for positively charged residues.}

We further investigated which protein features might be most important for apoplastic and cytoplasmic effector predictions in fungi and oomycetes. For this, we selected the most discriminative features that separate effectors from secreted proteins in saprophytes and brown algae. For fungal cytoplasmic effectors, the four most discriminative features are an enrichment for the positively charged amino acid lysine, low molecular weight, enrichment for amino acids with high flexibility, and enrichment for positively charged residues. Similarly, for oomycete cytoplasmic effectors, the four most discriminative features are an enrichment in the positively charged amino acid lysine, an enrichment for positively charged residues, depletion in surface exposed residues, and an enrichment for residues that frequently occur in $\alpha$ helices. An enrichment for positively charged amino acids such as lysine appears to be a unifying feature for both fungal and oomycete cytoplasmic effectors but not for apoplastic effectors
(Fig. 2). We further investigated the lysine content in the signal peptide regions (first 20 aa), N-terminal regions (the first third of the sequence after the signal peptide region), and the $\mathrm{C}$-terminal regions (last two-thirds of the sequence). Both fungal and oomycete cytoplasmic effectors were enriched for lysines in the $\mathrm{C}$-terminal region, suggesting that this is a feature of the mature protein after cleavage of the signal peptide, and after the RxLR region in oomycete effectors (Fig. 3). This feature could be related to effector function in the cytoplasm or the requirements for translocation.

Both apoplastic and cytoplasmic effectors have, on average, lower molecular weight than secreted nonpathogen proteins. Apoplastic fungal and oomycete effectors are both enriched for cysteines, which was not observed for oomycete cytoplasmic effectors (Fig. 2). An enrichment for cysteines was also observed for fungal cytoplasmic effectors. Taken together, this suggests that low molecular weight and a high cysteine content is generally a unifying feature for apoplastic effectors and low molecular

Table 3. Test sets for assessing the false-positive prediction rates for cytoplasmic and apoplastic effector prediction by EffectorP $3.0^{\mathrm{a}}$

\begin{tabular}{|c|c|c|c|c|c|}
\hline \multirow[b]{2}{*}{ Test set } & \multirow[b]{2}{*}{ Proteins $(n)$} & \multicolumn{2}{|c|}{ EffectorP 3.0} & \multicolumn{2}{|c|}{ EffectorP-fungi 3.0 } \\
\hline & & Cytoplasmic & Apoplastic & Cytoplasmic & Apoplastic \\
\hline \multicolumn{6}{|l|}{ Sets depleted in cytoplasmic proteins } \\
\hline $\begin{array}{l}\text { Plant proteins with annotated apoplastic } \\
\text { localization }\end{array}$ & 362 & $37(10.2 \%)$ & $75(20.7 \%)$ & $39(10.8 \%)$ & $74(20.4 \%)$ \\
\hline $\begin{array}{l}\text { Apoplastic proteome of Magnaporthe oryzae } \\
\text { (Kim et al. 2013) }\end{array}$ & 155 & $12(7.7 \%)$ & $32(20.6 \%)$ & $5(3.2 \%)$ & $32(20.6 \%)$ \\
\hline $\begin{array}{l}\text { Apoplastic proteome of Oryza sativa } \\
\text { (Kim et al. 2013) }\end{array}$ & 94 & $1(1.1 \%)$ & $23(24.5 \%)$ & $0(0 \%)$ & $23(24.5 \%)$ \\
\hline $\begin{array}{l}\text { Leaf apoplast proteome of Brassica napus } \\
\text { var. napus infected with Verticillium } \\
\text { longisporum (Floerl et al. 2008) }\end{array}$ & 8 & $0(0 \%)$ & $5(62.5 \%)$ & $0(0 \%)$ & $5(62.5 \%)$ \\
\hline $\begin{array}{l}\text { Leaf apoplast proteome of Arabidopsis } \\
\text { thaliana infected with V. longisporum } \\
\text { (Floerl et al. 2012) }\end{array}$ & 27 & $1(3.7 \%)$ & $7(25.9 \%)$ & $0(0 \%)$ & $8(29.6 \%)$ \\
\hline $\begin{array}{l}\text { Apoplastic proteome of Nicotiana } \\
\text { benthamiana leaves (Goulet et al. 2010) }\end{array}$ & 16 & $2(12.5 \%)$ & $10(62.5 \%)$ & $0(0 \%)$ & $11(68.8 \%)$ \\
\hline Fungal CAZYs (UniProt, reviewed entries) & 1,164 & $115(9.9 \%)$ & $232(19.9 \%)$ & $68(5.8 \%)$ & $231(19.8 \%)$ \\
\hline Fungal saprophyte secreted proteins & 24,432 & $2,018(8.3 \%)$ & $3,635(14.9 \%)$ & $1,625(6.7 \%)$ & $3,597(14.7 \%)$ \\
\hline $\begin{array}{l}\text { False-positive rate for cytoplasmic effector } \\
\text { prediction }\end{array}$ & 26,258 & $2,186(8.3 \%)$ & - & $1,737(6.6 \%)$ & - \\
\hline \multicolumn{6}{|l|}{ Sets depleted in apoplastic proteins } \\
\hline $\begin{array}{l}\text { Plant proteins with annotated cytoplasmic } \\
\text { localization }\end{array}$ & 3,843 & $1,970(51.3 \%)$ & $84(2.2 \%)$ & $1,355(37.5 \%)$ & $86(2.2 \%)$ \\
\hline $\begin{array}{l}\text { Fungal endoplasmic reticulum-localized } \\
\text { proteins }\end{array}$ & 71 & $23(38 \%)$ & $4(5.6 \%)$ & $16(22.5 \%)$ & $4(5.6 \%)$ \\
\hline Fungal Golgi-localized proteins & 19 & $4(21.1 \%)$ & $1(5.3 \%)$ & $3(15.8 \%)$ & $1(5.3 \%)$ \\
\hline Fungal vacuole proteins & 15 & $4(26.7 \%)$ & $0(0 \%)$ & $4(26.7 \%)$ & $0(0 \%)$ \\
\hline Human proteins & 20,238 & $7,314(36.1 \%)$ & $513(2.5 \%)$ & $5,790(28.6 \%)$ & $480(2.4 \%)$ \\
\hline $\begin{array}{l}\text { Bacterial type-III effectors (T3Enc) } \\
\text { (Hui et al. 2020) }\end{array}$ & 519 & $263(50.7 \%)$ & $17(3.3 \%)$ & $210(40.5 \%)$ & $17(3.3 \%)$ \\
\hline RxLR effector candidates (Win et al. 2007) & 358 & $331(92.5 \%)$ & $0(0 \%)$ & $249(69.6 \%)$ & $0(0 \%)$ \\
\hline $\begin{array}{l}\text { False-positive rate for apoplastic effector } \\
\text { prediction }\end{array}$ & 24,705 & - & $618(2.5 \%)$ & - & $587(2.4 \%)$ \\
\hline
\end{tabular}

${ }^{\mathrm{a}}$ In the test sets that are expected to be depleted in cytoplasmic proteins, EffectorP 3.0 has a false-positive rate for cytoplasmic effector prediction of $8.3 \%$. A lower false-positive rate of $2.5 \%$ is achieved by EffectorP 3.0 for apoplastic effector prediction on sets that are depleted in apoplastic proteins.

Table 4. Predicted localizations for cytoplasmic and apoplastic effectors that have experimental evidence for their localization from both the training and validation sets ${ }^{\mathrm{a}}$

\begin{tabular}{|c|c|c|c|c|c|c|}
\hline \multirow[b]{2}{*}{ Effectors $^{b}$} & \multirow[b]{2}{*}{$\begin{array}{l}\text { Proteins } \\
\quad(n)\end{array}$} & \multicolumn{2}{|c|}{ EffectorP $\mathbf{3 . 0}$} & \multicolumn{2}{|c|}{ EffectorP-fungi 3.0 } & \multirow{2}{*}{$\frac{\text { ApoplastP 1.0 }}{\begin{array}{c}\text { Apoplastic } \\
\text { proteins }\end{array}}$} \\
\hline & & $\begin{array}{l}\text { Cytoplasmic } \\
\text { effectors }\end{array}$ & $\begin{array}{l}\text { Apoplastic } \\
\text { effectors }\end{array}$ & $\begin{array}{l}\text { Cytoplasmic } \\
\text { effectors }\end{array}$ & $\begin{array}{l}\text { Apoplastic } \\
\text { effectors }\end{array}$ & \\
\hline Apoplastic & 57 & $7(12.3 \%)$ & $46(80.7 \%)$ & $12(10.9 \%)$ & $44(77.2 \%)$ & $44(77.2 \%)$ \\
\hline Cytoplasmic & 110 & $88(80 \%)$ & $15(13.6 \%)$ & 77 (70\%) & $9(15.8 \%)$ & $16(14.5 \%)$ \\
\hline
\end{tabular}

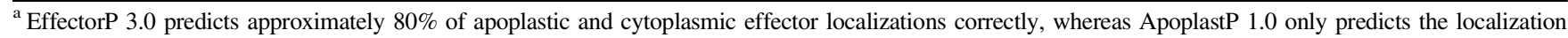
of approximately $77 \%$ of the apoplastic effectors correctly. Numbers in bold indicate the highest numbers of predicted effectors.

${ }^{\mathrm{b}}$ Effectors with experimental support from validation and training sets. 
weight and a high lysine content is a unifying feature for cytoplasmic effectors. Thus, selection of fungal cytoplasmic effector candidates for experimental validation should not be based on low molecular weight and a high cysteine content alone.

\section{Sets of infection-induced proteins are enriched for predicted effectors.}

Effectors are expressed during infection and, thus, secreted proteins encoded by genes that are expressed during infection
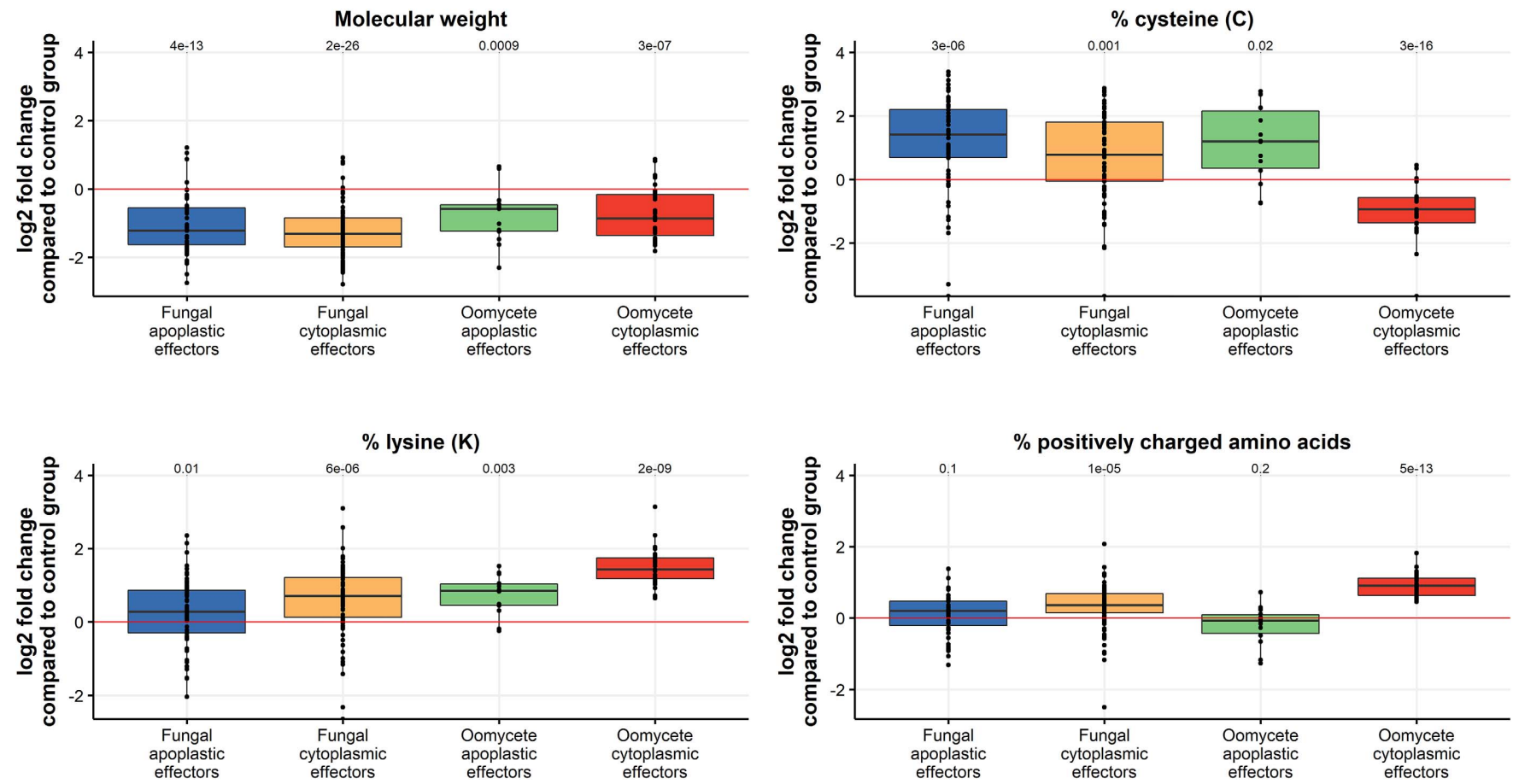

Fig. 2. Most discriminate features in fungal and oomycete effector prediction. The $\log _{2}$-fold change compared with the median of the control group (saprophyte- or brown-algae-secreted proteins) is shown. Fungal and oomycete effectors have, on average, lower molecular weight than saprophyte- or brown-algae-secreted proteins. A unifying feature for fungal and oomycete cytoplasmic effectors is an enrichment for positively charged amino acids, particularly lysines. Statistical significance was assessed with $t$ tests and adjusted with the Bonferroni correction for multiple testing.

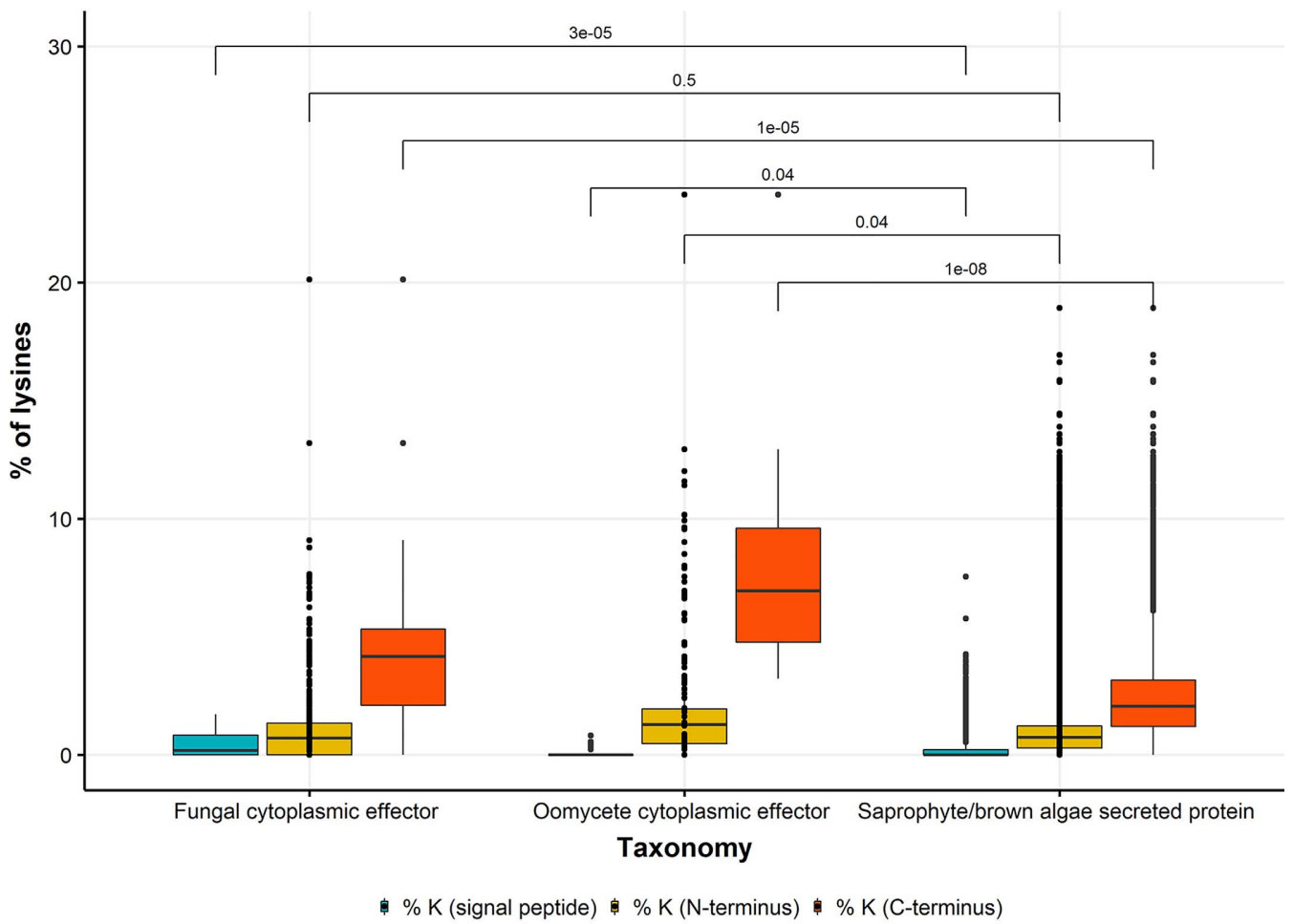

Fig. 3. C-terminal regions of fungal and oomycete effectors (last two-thirds of the sequence) are enriched for lysine residues. Statistical significance was assessed with $t$ tests and adjusted with the Bonferroni correction for multiple testing. 
are expected to be enriched for predicted effectors. We used several expression data sets from the literature to assess whether EffectorP 3.0 leads to improved effector predictions. All infection-induced effector candidate sets were enriched for predicted effectors by EffectorP 3.0 when compared with effector predictions on whole secretomes (Table 5). Furthermore, the predicted apoplastic and cytoplasmic localization of effector candidates corresponded well with the corresponding infection stage. For example, genes encoding for secreted proteins that are upregulated in biotrophic invasive hyphae in M. oryzae (Mosquera et al. 2009) were enriched for predicted cytoplasmic effectors, although in-planta-induced small secreted apoplastic effector candidates in Cladosporium fulvum (Mesarich et al. 2018) were enriched for predicted apoplastic effectors. We then used gene expression data of the obligate biotrophic fungal pathogen $P$. graminis f. sp. tritici 21-0 to investigate expression of predicted apoplastic and cytoplasmic effectors (Chen et al. 2017). This time course covered wheat infection from 2 to 7 days postinfection (dpi) as well as in vitro germinated spores and haustorial tissue (Upadhyaya et al. 2015). Rust haustoria enable nutrient uptake as well as the delivery of effectors into the host plant cell and, thus, were expected to be enriched for cytoplasmic effectors. In contrast, spores germinate on the leaf surface at the start of the infection cycle and, thus, were expected to be depleted for cytoplasmic effectors. We collected secreted proteins that were upregulated in germinated spores compared with haustorial tissue $(n=841)$ and secreted proteins that were upregulated in haustorial tissue compared with germinated spores $(n$ $=1,732$ ). EffectorP 3.0 predicted 22.1 and $21.9 \%$ of the secreted proteins upregulated in germinated spores as cytoplasmic and apoplastic effectors, respectively. In contrast, EffectorP 3.0 predicted 55.7 and $18.5 \%$ of the secreted proteins upregulated in haustoria as cytoplasmic and apoplastic effectors, respectively. Thus, as expected, secreted proteins upregulated in rust haustorial tissue were enriched for predicted cytoplasmic effectors with EffectorP 3.0.

\section{Obligate biotroph and animal parasite secretomes are highly enriched for predicted cytoplasmic effectors.}

We predicted apoplastic and cytoplasmic effectors in 92 fungal and oomycete secretomes (Table 6; Supplementary Data S1). The highest proportions of cytoplasmic effectors were predicted in the secretomes of the animal parasites Encephalitozoon cuniculi $(75.4 \%)$ and Enterocytozoon bieneusi $(72 \%)$, the animal pathogen Batrachochytrium dendrobatidis (55.6\%), the arbuscular mycorrhizal fungus Rhizophagus clarus (52\%), and the obligate biotrophic pathogens Albugo laibachii (49.4\%) and P. graminis f. sp. tritici $(44.7 \%)$. The highest proportions of apoplastic effectors was predicted in the secretomes of the hemibiotrophic pathogen Venturia inaequalis (24\%), the necrotrophic pathogen S. sclerotiorum (23.7\%), the arbuscular mycorrhizal fungus Gigaspora rosea $(22.5 \%)$, the obligate biotrophic pathogens $P$. striiformis f. sp. tritici $(21.3 \%)$ and P. graminis f. sp. tritici $(20.5 \%)$, as well as the hemibiotrophic pathogen $F$. graminearum (19.8\%). Overall, the secretomes of obligate biotrophs, biotrophic pathogens, hemibiotrophic pathogens, arbuscular mycorrhizal fungi, and animal pathogens or parasites had higher proportions of predicted cytoplasmic effectors than apoplastic effectors in their secretomes (Table 6). As expected, necrotrophic pathogens and ectomycorrhizal fungi were enriched for predicted apoplastic effectors.

Nonpathogenic fungi that colonize plants include endophytes as well as ectomycorrhizal and arbuscular mycorrhizal fungi, which establish close symbiotic association with plants. Symbiotic fungi such as arbuscular mycorrhizal fungi have dedicated feeding structures (arbuscules) and also secrete cytoplasmic effector proteins to suppress plant defense and promote symbiosis (Kloppholz et al. 2011; Plett et al. 2011). Indeed, EffectorP 3.0 predicted a high average proportion of cytoplasmic effectors $(40.6 \%)$ for the five tested arbuscular mycorrhizal fungal secretomes. In contrast, only $8.3 \%$ predicted cytoplasmic effectors occur, on average, in the saprophyte secretomes. However, we found a substantially higher proportion of predicted cytoplasmic effectors in yeasts $(15.6 \%)$. We further investigated the highquality functional annotations of the predicted effectors of the yeast Saccharomyces cerevisiae (Supplementary Tables S4 and S5). Of the 268 predicted secreted proteins, EffectorP 3.0 predicted 46 cytoplasmic effectors (17.2\%) and 29 apoplastic effectors $(10.8 \%)$. Most of the predicted cytoplasmic effectors have annotated intracellular subcellular localizations, suggesting that EffectorP 3.0 is predicting an intracellular signal and these proteins are nonsecreted false positives from SignalP 4.0 (Petersen

Table 5. Infection-induced genes encoding secreted proteins are enriched for predicted effectors by EffectorP 3.0

\begin{tabular}{|c|c|c|c|}
\hline \multirow[b]{2}{*}{ Test set } & \multirow[b]{2}{*}{ Proteins $(n)$} & \multicolumn{2}{|c|}{ Predicted by EffectorP 3.0 (apoplastic/cytoplasmic) (\%) } \\
\hline & & Effectors & Effectors in secretome \\
\hline $\begin{array}{l}\text { Colletotrichum higginsianum: Biotrophy-associated } \\
\text { effector candidates (Kleemann et al. 2012) }\end{array}$ & 102 & $62.7(48.4 / 51.6)$ & $26.6(67.3 / 32.7)$ \\
\hline $\begin{array}{l}\text { Cladosporium fulvum: In planta induced small } \\
\text { secreted apoplastic effector candidates (Mesarich } \\
\text { et al. 2018) }\end{array}$ & 75 & $94.7(85.9 / 14.1)$ & $29.5(61.4 / 38.6)$ \\
\hline $\begin{array}{l}\text { Magnaporthe oryzae: Genes with } \geq 50 \text {-fold } \\
\text { differential expression in biotrophic invasive } \\
\text { hyphae (Mosquera et al. 2009) }\end{array}$ & 15 & $100(33.3 / 66.7)$ & $38.9(49.4 / 50.6)$ \\
\hline $\begin{array}{l}\text { Blumeria graminis f. sp. hordei: Candidates for } \\
\text { secreted effector proteins (CSEPs) } \\
\text { (Pedersen et al. 2012) }\end{array}$ & 491 & $81.5(18 / 82)$ & $48.7(24.3 / 75.7)$ \\
\hline $\begin{array}{l}\text { Laccaria bicolor: Ectomycorrhiza-regulated small } \\
\text { secreted proteins (MiSSPs) (Martin et al. 2008) }\end{array}$ & 21 & $85.7(50 / 50)$ & $22.5(55.8 / 44.2)$ \\
\hline $\begin{array}{l}\text { Zymoseptoria tritici candidate effectors } \\
\quad(\text { Kettles et al. 2017) }\end{array}$ & 63 & $76.2(68.8 / 31.2)$ & $32.2(57.3 / 42.7)$ \\
\hline $\begin{array}{l}\text { Ustilago maydis effector candidates } \\
\text { (Tollot et al. 2016) }\end{array}$ & 198 & $49(30.9 / 69.1)$ & $35.7(37.7 / 62.3)$ \\
\hline $\begin{array}{l}\text { Leptosphaeria maculans highly expressed early } \\
\text { effector candidates (Gervais et al. 2017) }\end{array}$ & 49 & $83.7(41.5 / 58.5)$ & $24.3(58.9 / 41.1)$ \\
\hline $\begin{array}{l}\text { L. maculans highly expressed late effector } \\
\text { candidates (Gervais et al. 2017) }\end{array}$ & 50 & $62(48.4 / 51.6)$ & $24.3(58.9 / 41.1)$ \\
\hline $\begin{array}{l}\text { Bremia lactucae cell death inducing effector } \\
\text { candidates (Wood et al. 2020) }\end{array}$ & 11 & $72.7(0 / 100)$ & $51.6(20.2 / 79.8)$ \\
\hline
\end{tabular}


et al. 2011). This underlines the idea that accurate secretion prediction is a prerequisite for accurate EffectorP predictions. Current versions of SignalP (5.0 and 6.0) might reduce the number of false-positive secreted proteins; however, this might come at the cost of missing true-positive effectors in the secretomes (Sperschneider et al. 2015b).

\section{DISCUSSION}

Plant diseases and pests are a major threat to food security. Plant pathogens cause disease through secreted effector proteins, and their identification from genomic sequences is crucial for enhancing host-plant resistance and for improving crop resistance (Vleeshouwers and Oliver 2014). With the ever-increasing number of high-quality genome sequences, accurate computational prediction of effectors for subsequent experimental validation has become the bottleneck. Existing effector prediction methods return hundreds of candidates and can suffer from high false-positive rates (Sperschneider et al. 2015a), leading to low experimental validation success rates and a limited understanding of effector biology.

Fungal effector proteins are diverse in sequence, which complicates their prediction. Early approaches to fungal effector prediction were reliant on filtering secretomes for proteins of small size and high cysteine content. Such user-driven selection is generally of low accuracy and has been detrimental for advancing our understanding of effector biology because it is unable to uncover exceptions to the rules. For example, a simple classifier based on a small protein size ( $\leq 300$ aa) has an estimated falsepositive rate of $40 \%$ and a small, cysteine-rich classifier $(\leq 300$ aa and $\geq 4$ cysteines) has an estimated false-positive rate of $19 \%$ (Sperschneider et al. 2018a). A contrasting data-driven approach is machine learning that can automatically identify relevant patterns in data. A machine-learning model can be trained to recognize a particular concept based on its features in observed data and can then be applied to identify new instances of the concept in unseen data. EffectorP is such a machine-learning prediction tool for fungal effector prediction (Sperschneider et al. 2016, 2018a). EffectorP versions 1.0 and 2.0 had a major impact on the plant-pathogen community and introduced a shift in methodology from user-driven selection to data-driven selection of effectors. Thus far, EffectorP has been utilized to predict effectors across all major pathosystems. For example, EffectorP has been utilized for effector candidate finding in genome assemblies (Bertazzoni et al. 2021; Malar C et al. 2021), for prioritization of effector candidates for experimental validation (Degrave et al. 2021; Zhong et al. 2017), and in elucidating genome organization of plant pathogens (Luciano et al. 2019, Tsushima et al. 2019).

However, current effector prediction methods such as EffectorP 2.0 (Sperschneider et al. 2018a), deepredeff (Kristianingsih and MacLean 2021), or EffectorO (Nur et al. 2021) give a yesor-no answer as to whether a protein is a likely effector and do not deliver vital information for prioritization: Is the effector extracellular and does it function in the plant apoplast or is it cytoplasmic and does it enter plant cells? In oomycetes, the presence of conserved sequence motifs such as the RxLR motif have been used extensively for cytoplasmic effector prediction. However, the biological function of the RxLR motif in effector translocation has been debated (Ellis and Dodds 2011; Wawra et al. 2017). Furthermore, the RxLR motif is not conserved outside Phytophthora spp. and downy mildews and, thus, cannot be used for effector prediction alone in other oomycete species (Ai et al. 2020; Wood et al. 2020). Although oomycete sequence motif and Hidden Markov Model searches are wellestablished methods to predict cytoplasmic effectors, this will miss bona fide effectors that do not carry such signatures. Furthermore, apoplastic effector prediction in oomycetes is an unresolved problem.

Here, we took advantage of differences in apoplastic and cytoplasmic environments that allow for accurate prediction of pathogen proteins localizing to these compartments. EffectorP 3.0 can predict whether a secreted protein is an apoplastic effector, a cytoplasmic effector, or a noneffector. On our evaluation sets, we found that EffectorP 3.0 had higher accuracy than EffectorP 2.0, deepredeff, or EffectorO. It also was more accurate in predicting apoplastic localization in effectors than ApoplastP (Sperschneider et al. 2018b). We found that cytoplasmic effectors are enriched for positively charged amino acids in the $\mathrm{C}$ terminus in both fungi and oomycetes. In contrast, the deeplearning tool deepredeff found the most discriminative signal for effector prediction in the first 25 aa of the proteins (i.e., in the signal peptide region). In our tests, deepredeff had a high false-positive rate in nonpathogen secretomes, suggesting that the signal peptide region alone is unlikely to be the discriminative signal for effector function. A high cysteine content was an important component of prediction for apoplastic effectors. However, in some cases, this signal led to cysteine-rich cytoplasmic effectors being assigned a high probability of apoplastic localization. Some cytoplasmic effectors such as AvrP123

Table 6. Predicted effectors in fungal and oomycete secretomes ${ }^{a}$

\begin{tabular}{|c|c|c|c|c|c|c|}
\hline \multirow[b]{3}{*}{ Classification } & & & \multicolumn{4}{|c|}{ Effector predictions (\%) } \\
\hline & \multicolumn{2}{|c|}{ Number of } & \multicolumn{2}{|c|}{ EffectorP 3.0} & \multicolumn{2}{|c|}{ EffectorP-fungi 3.0} \\
\hline & Genomes & Proteins $^{b}$ & Cytoplasmic & Apoplastic & Cytoplasmic & Apoplastic \\
\hline Obligate biotrophs & 15 & 1,770 & $38.7^{*}$ & 12.1 & 32.5 & 11.3 \\
\hline Biotrophic pathogens & 2 & 438 & $23^{*}$ & 11.3 & 18.4 & 11.2 \\
\hline Hemibiotrophic pathogens & 16 & 1,474 & $18.2^{* *}$ & 17.3 & 15.1 & 16.7 \\
\hline Necrotrophic pathogens & 9 & 1,101 & $12.4^{* * *}$ & 17.9 & 9.7 & 17.6 \\
\hline Ectomycorrhizal fungi & 11 & 1,201 & $9.7 * * *$ & 12.9 & 8.3 & 12.7 \\
\hline Arbuscular mycorrhizal fungi & 5 & 861 & 40.6* & 16 & 35.4 & 15.2 \\
\hline Saprophytic fungi & 21 & 1,090 & $8.3^{* * *}$ & 14.4 & 6.9 & 14.2 \\
\hline Yeasts & 5 & 372 & $15.6^{* *}$ & 9.4 & 11.6 & 9.1 \\
\hline Brown algae & 4 & 1,254 & $13.4^{* *}$ & 4.1 & 8 & 3.9 \\
\hline Animal fungal pathogens & 7 & 558 & $23.4^{*}$ & 8.3 & 19.2 & 8.2 \\
\hline Animal parasite & 2 & 106 & $73.7^{\mathrm{NS}}$ & 2.7 & 63.8 & 3.2 \\
\hline
\end{tabular}

Vol. 35, No. 2, 2022 / 153 
(Zhang et al. 2018) contain high numbers of cysteine residues that can be involved in metal ion coordination, rather than disulfide bond formation. This potential for misprediction of localization should be kept in mind when interpreting EffectorP 3.0 results for cysteine-rich effector candidates. In the future, larger training data sets and additional experimental evidence for effector localization will allow for even more accurate predictions, as well as for investigations if any protein features are involved in effector translocation.

It is important to apply EffectorP 3.0 to secreted proteins only, and not to nonsecreted proteins. EffectorP 3.0 will predict a substantial proportion of intracellular, nonsecreted proteins as cytoplasmic effectors. For example, over half of plant cytoplasmic proteins are predicted as cytoplasmic effectors. This is not unexpected, because cytoplasmic effectors localize to the same environment as plant intracellular proteins. Again, accurate secretion prediction is a prerequisite for EffectorP 3.0. Finally, although EffectorP 3.0 returns probabilities for the likelihood that a secreted protein is an effector, we recommend that these are not overinterpreted. Ranking effector candidates according to their expression during infection with RNAsequencing (RNA-seq) data or through structural similarity to known effectors are recommended practices for effector candidate prioritization.

\section{MATERIALS AND METHODS}

\section{Curation of positive and negative training data.}

Effector sequences were collected through literature searches. For the negative training sets, we predicted secretomes from a wide range of fungal and oomycete genomes (Supplementary Table S1) with SignalP 4.1 (-t euk -u 0.34 -U 0.34) (Petersen et al. 2011) and TMHMM 2.0 (Krogh et al. 2001). A fungal protein was called secreted if it was predicted to have a signal peptide and had no transmembrane domains. A secreted oomycete protein was defined as an RxLR protein if it contained the RxLR motif in the first 100 aa. We curated five secreted protein sets: (i) a homology-reduced set of secreted proteins with an RxLR motif from plant-pathogenic oomycetes together with secreted proteins from biotrophic or hemibiotrophic fungi, (ii) a homology-reduced set of secreted proteins without an RxLR motif from plant-pathogenic oomycetes together with secreted proteins from necrotrophic or hemibiotrophic fungi, (iii) a set of secreted fungal saprophyte proteins and secreted proteins from brown algae, (iv) a set of secreted fungal ectomycorrhizal proteins, and (v) a set of secreted proteins from animal-pathogenic fungi and animal-pathogenic oomycetes. Proteins in the negative sets that shared sequence homology to an effector in the positive training set were excluded and protein sets were homology reduced, both with cd-hit 4.8.1 (-c 0.9) (Fu 2012).

\section{Machine-learning model training and feature extraction.}

We used a variety of protein features in classification: (i) amino acid frequencies, (ii) molecular weight, (iii) percentage of positively charged amino acids ( $\mathrm{K}$ and $\mathrm{R}$ ) in the sequence, (iv) percentage of negatively charged amino acids ( $\mathrm{D}$ and $\mathrm{E}$ ) in the sequence, (v) average surface exposure of amino acids in the sequence (Janin 1979), (vi) average hydrophobicity of amino acids in the sequence (Fauchere and Pliska 1983), (vii) average polarity of amino acids in the sequence (Zimmerman et al. 1968), (viii) average flexibility of amino acids in the sequence (Vihinen et al. 1994), (ix) frequency of aromatic amino acids $(\mathrm{F}$, $\mathrm{H}, \mathrm{W}$, and $\mathrm{Y}$ ) in the sequence, ( $\mathrm{x}$ ) frequency of polar amino acids $(\mathrm{D}, \mathrm{E}, \mathrm{H}, \mathrm{K}, \mathrm{N}, \mathrm{Q}, \mathrm{R}, \mathrm{S}, \mathrm{T}$, and $\mathrm{Z}$ ) in the sequence, (xi) average disorder propensity of amino acids in the sequence (Dunker et al. 2001), (xii) average bulkiness of amino acids in the sequence (Zimmerman et al. 1968), (xiii) average $\alpha$ helix frequency for amino acids in the sequence (Nagano 1973), (xiv) average $\beta$ sheet frequency for amino acids in the sequence (Nagano 1973), and (xv) average coil frequency for amino acids in the sequence (Nagano 1973). The WEKA tool box (version 3.8.4) was used to train and evaluate the performance of different machine-learning classifiers (Hall et al. 2009).

For the effector prediction models, we took randomly selected samples of each negative training data set to give a ratio of $3: 1$ to the number of positive training examples. We then used WEKA to train Naïve Bayes classifiers on each of the negative datasets with the same positive training set. We then repeated this procedure and trained $\mathrm{C} 4.5$ decision trees (J48 model in WEKA) on each of the negative datasets. For each set of 100 models, we selected the best-performing models as those with the highest negative predictive value [true negatives/(true negatives + false negatives)], consisting of 5 Naïve Bayes classifiers and $5 \mathrm{C} 4.5$ decision trees that discriminate between apoplastic effectors and secreted pathogen proteins, 5 Naïve Bayes classifiers and $5 \mathrm{C} 4.5$ decision trees that discriminate between apoplastic effectors and secreted saprophyte or brown algae proteins, 5 Naïve Bayes classifiers and $5 \mathrm{C} 4.5$ decision trees that discriminate between apoplastic effectors and secreted animal-pathogenic pathogen proteins, 5 Naïve Bayes classifiers and $5 \mathrm{C} 4.5$ decision trees that discriminate between cytoplasmic effectors and secreted pathogen proteins, 5 Naïve Bayes classifiers and $5 \mathrm{C} 4.5$ decision trees that discriminate between cytoplasmic effectors and secreted saprophyte or brown algae proteins, and 5 Naïve Bayes classifiers and $5 \mathrm{C} 4.5$ decision trees that discriminate between cytoplasmic effectors and secreted fungal ectomycorrhizal proteins. The ensemble classifier called EffectorP 3.0 returned a final prediction using a soft voting approach, which predicted the class label based on average probabilities for "apoplastic effector", "cytoplasmic effector", and "noneffector" calculated by each classifier. Soft voting then returned the class with the highest average probability as the result. A protein was classified as an apoplastic effector if the average probability for the class apoplastic effector was higher than the average probability for the class cytoplasmic effector and the class noneffector. A protein was classified as a cytoplasmic effector if the average probability for the class cytoplasmic effector was higher than the average probability for the class apoplastic effector and the class noneffector. If a secreted protein was predicted as both an apoplastic and cytoplasmic effector, EffectorP 3.0 reported it as duallocalized and the class with the highest probability as its likely localization. Because the number of cytoplasmic fungal effectors was sufficiently large, we also trained a fungal-specific cytoplasmic model with the same negative data sets and apoplastic model as above (EffectorP-fungi 3.0). Weka's CorrelationAttributeEval + Ranker method were used to find the most discriminative features for classification.

All plots were produced using ggplot2 (Wickham 2016) and statistical significance was assessed with $t$ tests using the ggsignif package and adjusted with the Bonferroni correction for multiple testing.

\section{Collection of validation sets.}

Validation sets were collected from UniProt with the following search terms. Plant proteins with annotated apoplastic localization: locations: (location: "Apoplast [SL-0019]"), length: [50 TO *], taxonomy: "Viridiplantae [33090]", and reviewed: "yes"; plant proteins with annotated cytoplasmic localization: taxonomy: "Viridiplantae [33090]", locations: (location: "Cytoplasm [SL0086]"), length: [50 TO *], and reviewed: "yes"; and fungal CAZYs: taxonomy: "Fungi [4751]", database: cazy, and reviewed: "yes". All other sets were collected from the literature and are online. 
RNA-seq differential expression analysis.

RNA reads from germinated spores and haustorial tissue of $P$. graminis f. sp. tritici 21-0 were obtained from NCBI BioProject PRJNA253722 (Upadhyaya et al. 2015), although reads from an infection time course (Chen et al. 2017) were obtained from NCBI BioProject PRJNA415866. Salmon v.1.1.0 (Patro et al. 2017) was used to align reads to the $P$. graminis f. sp. tritici 21-0 transcripts and to estimate transcript abundances in each sample (salmon index -keepDuplicates and salmon quant -validateMappings). We used tximport and DESeq2 (Love et al. 2014) to assess gene differential expression.

\section{ACKNOWLEDGMENTS}

J. Sperschneider is supported by an Australian Research Council Discovery Early Career Researcher Award (DE190100066).

\section{AUTHOR-RECOMMENDED INTERNET RESOURCES}

EffectorP 3.0: http://effectorp.csiro.au

EffectorP 3.0 data: https://github.com/JanaSperschneider/EffectorP-3.0-Data ggsignif package: https://cran.r-project.org/web/packages/ggsignif/index.html

\section{LITERATURE CITED}

Ai, G., Yang, K., Ye, W., Tian, Y., Du, Y., Zhu, H., Li, T., Xia, Q., Shen, D., Peng, H., Jing, M., Xia, A., and Dou, D. 2020. Prediction and characterization of RXLR effectors in Pythium species. Mol. Plant-Microbe Interact. 33:1046-1058.

Bertazzoni, S., Jones, D. A. B., Phan, H. T., Tan, K. C., and Hane, J. K. 2021. Chromosome-level genome assembly and manually-curated proteome of model necrotroph Parastagonospora nodorum Sn15 reveals a genome-wide trove of candidate effector homologs, and redundancy of virulence-related functions within an accessory chromosome. BMC Genomics 22:382.

Chen, J., Upadhyaya, N. M., Ortiz, D., Sperschneider, J., Li, F., Bouton, C., Breen, S., Dong, C., Xu, B., Zhang, X., Mago, R., Newell, K., Xia, X., Bernoux, M., Taylor, J. M., Steffenson, B., Jin, Y., Zhang, P., Kanyuka, K., Figueroa, M., Ellis, J. G., Park, R. F., and Dodds, P. N. 2017. Loss of AvrSr50 by somatic exchange in stem rust leads to virulence for Sr50 resistance in wheat. Science 358:1607-1610.

De Wit, P. J. 2016. Apoplastic fungal effectors in historic perspective; a personal view. New Phytol. 212:805-813.

Degrave, A., Wagner, M., George, P., Coudard, L., Pinochet, X., Ermel, M., Gay, E. J., Fudal, I., Moreno-Rico, O., Rouxel, T., and Balesdent, M.-H. 2021. A new avirulence gene of Leptosphaeria maculans, AvrLm14, identifies a resistance source in American broccoli (Brassica oleracea) genotypes. Mol. Plant Pathol. 22:1599-1612.

Dunker, A. K., Lawson, J. D., Brown, C. J., Williams, R. M., Romero, P., Oh, J. S., Oldfield, C. J., Campen, A. M., Ratliff, C. M., Hipps, K. W., Ausio, J., Nissen, M. S., Reeves, R., Kang, C., Kissinger, C. R., Bailey, R. W., Griswold, M. D., Chiu, W., Garner, E. C., and Obradovic, Z. 2001. Intrinsically disordered protein. J. Mol. Graph. Model. 19:26-59.

Ellis, J. G., and Dodds, P. N. 2011. Showdown at the RXLR motif: Serious differences of opinion in how effector proteins from filamentous eukaryotic pathogens enter plant cells. Proc. Natl. Acad. Sci. U.S.A. 108:14381-14382.

Fauchere, J.-L., and Pliska, V. E. 1983. Hydrophobic parameters pi of amino acid side chains from partitioning of $\mathrm{N}$-acetyl-amino-acid amides. Eur. J. Med. Chem. 18:369-375.

Floerl, S., Druebert, C., Majcherczyk, A., Karlovsky, P., Kues, U., and Polle, A. 2008. Defence reactions in the apoplastic proteome of oilseed rape (Brassica napus var. napus) attenuate Verticillium longisporum growth but not disease symptoms. BMC Plant Biol. 8:129.

Floerl, S., Majcherczyk, A., Possienke, M., Feussner, K., Tappe, H., Gatz, C., Feussner, I., Kues, U., and Polle, A. 2012. Verticillium longisporum infection affects the leaf apoplastic proteome, metabolome, and cell wall properties in Arabidopsis thaliana. PLoS One 7:e31435.

Fu, L., Niu, B., Zhu, Z., Wu, S., and Li, W. 2012. CD-HIT: Accelerated for clustering the next-generation sequencing data. Bioinformatics 28 : 3150-3152.

Galán, J. E., Lara-Tejero, M., Marlovits, T. C., and Wagner, S. 2014. Bacterial type III secretion systems: Specialized nanomachines for protein delivery into target cells. Annu. Rev. Microbiol. 68:415-438.
Gervais, J., Plissonneau, C., Linglin, J., Meyer, M., Labadie, K., Cruaud, C., Fudal, I., Rouxel, T., and Balesdent, M. H. 2017. Different waves of effector genes with contrasted genomic location are expressed by Leptosphaeria maculans during cotyledon and stem colonization of oilseed rape. Mol. Plant Pathol. 18:1113-1126.

Giraldo, M. C., Dagdas, Y. F., Gupta, Y. K., Mentlak, T. A., Yi, M., Martinez-Rocha, A. L., Saitoh, H., Terauchi, R., Talbot, N. J., and Valent, B. 2013. Two distinct secretion systems facilitate tissue invasion by the rice blast fungus Magnaporthe oryzae. Nat. Commun. 4:1996.

Glazebrook, J. 2005. Contrasting mechanisms of defense against biotrophic and necrotrophic pathogens. Annu. Rev. Phytopathol. 43:205227.

Goulet, C., Goulet, C., Goulet, M. C., and Michaud, D. 2010. 2-DE proteome maps for the leaf apoplast of Nicotiana benthamiana. Proteomics 10:2536-2544.

Hall, M., Frank, E., Holmes, G., Pfahringer, B., Reutemann, P., and Witten, I. H. 2009. The WEKA data mining software: An update. ACM SIGKDD Explor. Newsl. 11:10-18.

Hui, X., Chen, Z., Lin, M., Zhang, J., Hu, Y., Zeng, Y., Cheng, X., OuYang, L., Sun, M. A., White, A. P., and Wang, Y. 2020. T3SEpp: An integrated prediction pipeline for bacterial type III secreted effectors. mSystems 5.

Janin, J. 1979. Surface and inside volumes in globular proteins. Nature 277:491-492.

Jones, D. A. B., Rozano, L., Debler, J. W., Mancera, R. L., Moolhuijzen, P. M., and Hane, J. K. 2021. An automated and combinative method for the predictive ranking of candidate effector proteins of fungal plant pathogens. Sci. Rep. 11:19731.

Kettles, G. J., Bayon, C., Canning, G., Rudd, J. J., and Kanyuka, K. 2017. Apoplastic recognition of multiple candidate effectors from the wheat pathogen Zymoseptoria tritici in the nonhost plant Nicotiana benthamiana. New Phytol. 213:338-350.

Khang, C. H., Berruyer, R., Giraldo, M. C., Kankanala, P., Park, S. Y., Czymmek, K., Kang, S., and Valent, B. 2010. Translocation of Magnaporthe oryzae effectors into rice cells and their subsequent cellto-cell movement. Plant Cell 22:1388-1403.

Kim, S. G., Wang, Y., Lee, K. H., Park, Z. Y., Park, J., Wu, J., Kwon, S. J., Lee, Y. H., Agrawal, G. K., Rakwal, R., Kim, S. T., and Kang, K. Y. 2013. In-depth insight into in vivo apoplastic secretome of riceMagnaporthe oryzae interaction. J. Proteomics 78:58-71.

Kleemann, J., Rincon-Rivera, L. J., Takahara, H., Neumann, U., van Themaat, E. V. L., van der Does, H. C., Hacquard, S., Stüber, K., Will, I., Schmalenbach, W., Schmelzer, E., and O'Connell, R. J. 2012. Sequential delivery of host-induced virulence effectors by appressoria and intracellular hyphae of the phytopathogen Colletotrichum higginsianum. PLoS Pathog. 8:e1002643.

Kloppholz, S., Kuhn, H., and Requena, N. 2011. A secreted fungal effector of Glomus intraradices promotes symbiotic biotrophy. Curr. Biol. 21:1204-1209.

Kristianingsih, R., and MacLean, D. 2021. Accurate plant pathogen effector protein classification ab initio with deepredeff: An ensemble of convolutional neural networks. BMC Bioinformatics 22:372.

Krogh, A., Larsson, B., von Heijne, G., and Sonnhammer, E. L. 2001. Predicting transmembrane protein topology with a hidden Markov model: Application to complete genomes. J. Mol. Biol. 305:567-580.

Lo Presti, L., and Kahmann, R. 2017. How filamentous plant pathogen effectors are translocated to host cells. Curr. Opin. Plant Biol. 38:19-24.

Lo Presti, L., Lanver, D., Schweizer, G., Tanaka, S., Liang, L., Tollot, M., Zuccaro, A., Reissmann, S., and Kahmann, R. 2015. Fungal effectors and plant susceptibility. Annu. Rev. Plant Biol. 66:513-545.

Love, M. I., Huber, W., and Anders, S. 2014. Moderated estimation of fold change and dispersion for RNA-seq data with DESeq2. Genome Biol. 15:550.

Luciano, L. B. G., Tsai, I. J., Chuma, I., Tosa, Y., Chen, Y.-H., Li, J.-Y., Li, M.-Y., Lu, M.-Y. J., Nakayashiki, H., and Li, W.-H. 2019. Blast fungal genomes show frequent chromosomal changes, gene gains and losses, and effector gene turnover. Mol. Biol. Evol. 36: 1148-1161.

Ludwig, N., Reissmann, S., Schipper, K., Gonzalez, C., Assmann, D., Glatter, T., Moretti, M., Ma, L. S., Rexer, K. H., Snetselaar, K., and Kahmann, R. 2021. A cell surface-exposed protein complex with an essential virulence function in Ustilago maydis. Nat. Microbiol. 6:722730.

Malar C, M., Kruger, M., Kruger, C., Wang, Y., Stajich, J. E., Keller, J., Chen, E. C. H., Yildirir, G., Villeneuve-Laroche, M., Roux, C., Delaux, P. M., and Corradi, N. 2021. The genome of Geosiphon pyriformis reveals ancestral traits linked to the emergence of the arbuscular mycorrhizal symbiosis. Curr. Biol. 31:1578-1580. 
Martin, F., Aerts, A., Ahrén, D., Brun, A., Danchin, E. G. J., Duchaussoy, F., Gibon, J., Kohler, A., Lindquist, E., Pereda, V., Salamov, A., Shapiro, H. J., Wuyts, J., Blaudez, D., Buée, M., Brokstein, P., Canbäck, B., Cohen, D., Courty, P. E., Coutinho, P. M., Delaruelle, C., Detter, J. C., Deveau, A., DiFazio, S., Duplessis, S., FraissinetTachet, L., Lucic, E., Frey-Klett, P., Fourrey, C., Feussner, I., Gay, G., Grimwood, J., Hoegger, P. J., Jain, P., Kilaru, S., Labbé, J., Lin, Y. C., Legué, V., Le Tacon, F., Marmeisse, R., Melayah, D., Montanini, B., Muratet, M., Nehls, U., Niculita-Hirzel, H., Oudot-Le Secq, M. P., Peter, M., Quesneville, H., Rajashekar, B., Reich, M., Rouhier, N., Schmutz, J., Yin, T., Chalot, M., Henrissat, B., Kües, U., Lucas, S., Van de Peer, Y., Podila, G. K., Polle, A., Pukkila, P. J., Richardson, P. M., Rouzé, P., Sanders, I. R., Stajich, J. E., Tunlid, A., Tuskan, G., and Grigoriev, I. V. 2018. The genome of Laccaria bicolor provides insights into mycorrhizal symbiosis. Nature 452:88-92.

Mesarich, C. H., Ökmen, B., Rovenich, H., Griffiths, S. A., Wang, C., Karimi Jashni, M., Mihajlovski, A., Collemare, J., Hunziker, L., Deng, C. H., van der Burgt, A., Beenen, H. G., Templeton, M. D., Bradshaw, R. E., and de Wit, P. J. G. M. 2018. Specific hypersensitive response-associated recognition of new apoplastic effectors from Cladosporium fulvum in wild tomato. Mol. Plant-Microbe Interact. 31:145-162.

Mitchum, M. G., Hussey, R. S., Baum, T. J., Wang, X., Elling, A. A., Wubben, M., and Davis, E. L. 2013. Nematode effector proteins: An emerging paradigm of parasitism. New Phytol. 199:879-894.

Mosquera, G., Giraldo, M. C., Khang, C. H., Coughlan, S., and Valent, B. 2009. Interaction transcriptome analysis identifies Magnaporthe oryzae BAS1-4 as biotrophy-associated secreted proteins in rice blast disease. Plant Cell 21:1273-1290.

Nagano, K. 1973. Logical analysis of the mechanism of protein folding: I. Predictions of helices, loops and $\beta$-structures from primary structure. J. Mol. Biol. 75:401-420.

Nur, M., Wood, K., and Michelmore, R. 2021. EffectorO: Motifindependent prediction of effectors in oomycete genomes using machine learning and lineage specificity. bioRxiv. 19.436227.

Palma-Guerrero, J., Ma, X., Torriani, S. F., Zala, M., Francisco, C. S., Hartmann, F. E., Croll, D., and McDonald, B. A. 2017. Comparative transcriptome analyses in Zymoseptoria tritici reveal significant differences in gene expression among strains during plant infection. Mol. Plant-Microbe Interact. 30:231-244.

Patro, R., Duggal, G., Love, M. I., Irizarry, R. A., and Kingsford, C. 2017. Salmon provides fast and bias-aware quantification of transcript expression. Nat. Methods 14:417-419.

Pedersen, C., Ver Loren van Themaat, E., McGuffin, L. J., Abbott, J. C., Burgis, T. A., Barton, G., Bindschedler, L. V., Lu, X., Maekawa, T., Wessling, R., Cramer, R., Thordal-Christensen, H., Panstruga, R., and Spanu, P. D. 2012. Structure and evolution of barley powdery mildew effector candidates. BMC Genomics 13:694.

Petersen, T. N., Brunak, S., von Heijne, G., and Nielsen, H. 2011. SignalP 4.0: Discriminating signal peptides from transmembrane regions. Nat. Methods 8:785-786

Plett, J. M., Kemppainen, M., Kale, S. D., Kohler, A., Legue, V., Brun, A., Tyler, B. M., Pardo, A. G., and Martin, F. 2011. A secreted effector protein of Laccaria bicolor is required for symbiosis development. Curr. Biol. 21:1197-1203.

Rodriguez, P. A., and Bos, J. I. 2013. Toward understanding the role of aphid effectors in plant infestation. Mol. Plant-Microbe Interact. 26:25-30.

Sánchez-Vallet, A., Hartmann, F. E., Marcel, T. C., and Croll, D. 2018. Nature's genetic screens: Using genome-wide association studies for effector discovery. Mol. Plant Pathol. 19:3-6.

Saunders, D. G., Win, J., Cano, L. M., Szabo, L. J., Kamoun, S., and Raffaele, S. 2012. Using hierarchical clustering of secreted protein families to classify and rank candidate effectors of rust fungi. PLoS One 7:e29847.

Savary, S., Willocquet, L., Pethybridge, S. J., Esker, P., McRoberts, N., and Nelson, A. 2019. The global burden of pathogens and pests on major food crops. Nat. Ecol. Evol. 3:430-439.

Schornack, S., van Damme, M., Bozkurt, T. O., Cano, L. M., Smoker, M., Thines, M., Gaulin, E., Kamoun, S., and Huitema, E. 2010. Ancient class of translocated oomycete effectors targets the host nucleus. Proc. Natl. Acad. Sci. U.S.A. 107:17421-17426.

Sperschneider, J., Catanzariti, A. M., DeBoer, K., Petre, B., Gardiner, D. M., Singh, K. B., Dodds, P. N., and Taylor, J. M. 2017. LOCALIZER: Subcellular localization prediction of both plant and effector proteins in the plant cell. Sci. Rep. 7:44598.

Sperschneider, J., Dodds, P. N., Gardiner, D. M., Manners, J. M., Singh, K. B., and Taylor, J. M. 2015a. Advances and challenges in computational prediction of effectors from plant pathogenic fungi. PLoS Pathog. 11:e1004806.
Sperschneider, J., Dodds, P. N., Gardiner, D. M., Singh, K. B., and Taylor, J. M. 2018a. Improved prediction of fungal effector proteins from secretomes with EffectorP 2.0. Mol. Plant Pathol. 19:2094-2110.

Sperschneider, J., Dodds, P. N., Singh, K. B., and Taylor, J. M. 2018b. APOPLASTP: Prediction of effectors and plant proteins in the apoplast using machine learning. New Phytol. 217:1764-1778.

Sperschneider, J., Gardiner, D. M., Dodds, P. N., Tini, F., Covarelli, L., Singh, K. B., Manners, J. M., and Taylor, J. M. 2016. EffectorP: Predicting fungal effector proteins from secretomes using machine learning. New Phytol. 210:743-761.

Sperschneider, J., Williams, A. H., Hane, J. K., Singh, K. B., and Taylor, J. M. 2015b. Evaluation of secretion prediction highlights differing approaches needed for oomycete and fungal effectors. Front. Plant Sci. 6:1168.

Stergiopoulos, I., and de Wit, P. J. 2009. Fungal effector proteins. Annu. Rev. Phytopathol. 47:233-263.

Tanaka, S., and Kahmann, R. 2021. Cell wall-associated effectors of plant-colonizing fungi. Mycologia 113:247-260.

Tollot, M., Assmann, D., Becker, C., Altmuller, J., Dutheil, J. Y., Wegner, C. E., and Kahmann, R. 2016. The WOPR protein Ros1 is a master regulator of sporogenesis and late effector gene expression in the maize pathogen Ustilago maydis. PLoS Pathog. 12:e1005697.

Tsushima, A., Gan, P., Kumakura, N., Narusaka, M., Takano, Y., Narusaka, Y., and Shirasu, K. 2019. Genomic plasticity mediated by transposable elements in the plant pathogenic fungus Colletotrichum higginsianum. Genome Biol. Evol. 11:1487-1500.

Upadhyaya, N. M., Garnica, D. P., Karaoglu, H., Sperschneider, J., Nemri, A., Xu, B., Mago, R., Cuomo, C. A., Rathjen, J. P., Park, R. F., Ellis, J. G., and Dodds, P. N. 2015. Comparative genomics of Australian isolates of the wheat stem rust pathogen Puccinia graminis f. sp. tritici reveals extensive polymorphism in candidate effector genes. Front. Plant Sci. 5:759.

Upadhyaya, N. M., Mago, R., Panwar, V., Hewitt, T., Luo, M., Chen, J., Sperschneider, J., Nguyen-Phuc, H., Wang, A., Ortiz, D., Hac, L., Bhatt, D., Li, F., Zhang, J., Ayliffe, M., Figueroa, M., Kanyuka, K., Ellis, J. G., and Dodds, P. N. 2021. Genomics accelerated isolation of a new stem rust avirulence gene-wheat resistance gene pair. Nat. Plants 7:1220-1228.

Vihinen, M., Torkkila, E., and Riikonen, P. 1994. Accuracy of protein flexibility predictions. Proteins 19:141-149.

Vleeshouwers, V. G. A. A., and Oliver, R. P. 2014. Effectors as tools in disease resistance breeding against biotrophic, hemibiotrophic, and necrotrophic plant pathogens. Mol. Plant-Microbe Interact. 27:196-206.

Wawra, S., Trusch, F., Matena, A., Apostolakis, K., Linne, U., Zhukov, I., Stanek, J., Kozminski, W., Davidson, I., Secombes, C. J., Bayer, P., and van West, P. 2017. The RxLR motif of the host targeting effector AVR3a of Phytophthora infestans is cleaved before secretion. Plant Cell 29:1184-1195.

Whisson, S. C., Boevink, P. C., Moleleki, L., Avrova, A. O., Morales, J. G., Gilroy, E. M., Armstrong, M. R., Grouffaud, S., van West, P., Chapman, S., Hein, I., Toth, I. K., Pritchard, L., and Birch, P. R. 2007. A translocation signal for delivery of oomycete effector proteins into host plant cells. Nature 450:115-118.

Wickham, H. 2016. ggplot2: Elegant Graphics for Data Analysis. Springer-Verlag, New York, NY, U.S.A. https://ggplot2.tidyverse.org

Win, J., Morgan, W., Bos, J., Krasileva, K. V., Cano, L. M., ChaparroGarcia, A., Ammar, R., Staskawicz, B. J., and Kamoun, S. 2007. Adaptive evolution has targeted the C-terminal domain of the RXLR effectors of plant pathogenic oomycetes. Plant Cell 19:2349-2369.

Wood, K. J., Nur, M., Gil, J., Fletcher, K., Lakeman, K., Gann, D., Gothberg, A., Khuu, T., Kopetzky, J., Naqvi, S., Pandya, A., Zhang, C., Maisonneuve, B., Pel, M., and Michelmore, R. 2020. Effector prediction and characterization in the oomycete pathogen Bremia lactucae reveal host-recognized WY domain proteins that lack the canonical RXLR motif. PLoS Pathog. 16:e1009012.

Zhang, X., Farah, N., Rolston, L., Ericsson, D. J., Catanzariti, A. M., Bernoux, M., Ve, T., Bendak, K., Chen, C., Mackay, J. P., Lawrence, G. J., Hardham, A., Ellis, J. G., Williams, S. J., Dodds, P. N., Jones, D. A., and Kobe, B. 2018. Crystal structure of the Melampsora lini effector AvrP reveals insights into a possible nuclear function and recognition by the flax disease resistance protein P. Mol. Plant Pathol. 19:1196-1209.

Zhong, Z., Marcel, T. C., Hartmann, F. E., Ma, X., Plissonneau, C., Zala, M., Ducasse, A., Confais, J., Compain, J., Lapalu, N., Amselem, J., McDonald, B. A., Croll, D., and Palma-Guerrero, J. 2017. A small secreted protein in Zymoseptoria tritici is responsible for avirulence on wheat cultivars carrying the Stb6 resistance gene. New Phytol. 214:619-631.

Zimmerman, J. M., Eliezer, N., and Simha, R. 1968. The characterization of amino acid sequences in proteins by statistical methods. J. Theor. Biol. 21:170-201. 